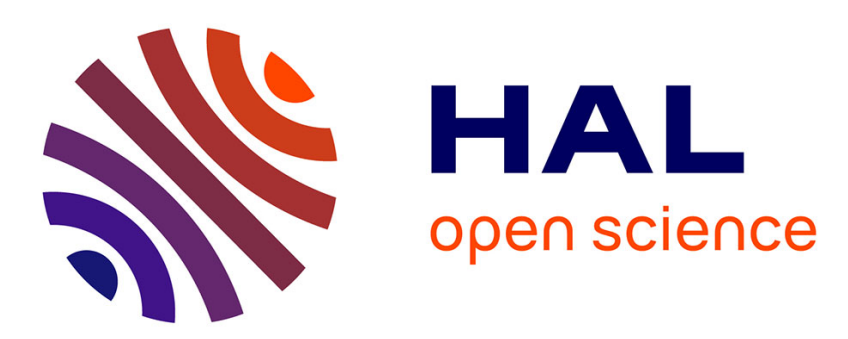

\title{
From Blue to White luminescence in Cerium-doped Aluminum Oxynitride: Electronic Structure and Local Chemistry Perspectives
}

\author{
Alaa E Giba, Philippe Pigeat, Stéphanie Bruyere, Hervé Rinnert, Flavio \\ Soldera, Frank Mücklich, David Horwat
}

\section{To cite this version:}

Alaa E Giba, Philippe Pigeat, Stéphanie Bruyere, Hervé Rinnert, Flavio Soldera, et al.. From Blue to White luminescence in Cerium-doped Aluminum Oxynitride: Electronic Structure and Local Chemistry Perspectives. Journal of Physical Chemistry C, 2018, 122 (37), pp.21623-21631. 10.1021/acs.jpcc.8b06992 . hal-03281682

\section{HAL Id: hal-03281682 \\ https://hal.science/hal-03281682}

Submitted on 8 Jul 2021

HAL is a multi-disciplinary open access archive for the deposit and dissemination of scientific research documents, whether they are published or not. The documents may come from teaching and research institutions in France or abroad, or from public or private research centers.
L'archive ouverte pluridisciplinaire HAL, est destinée au dépôt et à la diffusion de documents scientifiques de niveau recherche, publiés ou non, émanant des établissements d'enseignement et de recherche français ou étrangers, des laboratoires publics ou privés. 
From Blue to White luminescence in Cerium-doped Aluminum Oxynitride: Electronic Structure and Local Chemistry Perspectives

\author{
Alaa E. Giba, ${ }^{1,2,3}$ Philippe Pigeat, ${ }^{1}$ Stéphanie Bruyere, ${ }^{1}$ Hervé Rinnert, ${ }^{1}$ Flavio Soldera, ${ }^{2}$ \\ Frank Mücklich, ${ }^{2}$ David Horwat ${ }^{1 *}$
}

${ }^{1}$ Université de Lorraine, CNRS, IJL, F-54000 Nancy, France

${ }^{2}$ Department Materials Science and Engineering, Saarland University, D-66123 Saarbrücken, Germany.

${ }^{3}$ National Institute of Laser Enhanced Sciences, Cairo University, Giza 12613, Egypt.

* Contact: david.horwat@univ-lorraine.fr

Keywords: cerium, AlN, thin films, blue emissions, white light

\begin{abstract}
The excellent physical and chemical properties of aluminum oxynitride, $\mathrm{Al}(\mathrm{O}) \mathrm{N}$, along with the tunable luminescence features of cerium ions $(\mathrm{Ce})$ hold a promising future in white light sources based on chip technology. Manipulation of the light emission color from blue to green, to yellow and finally to white is demonstrated for the first time in Ce-doped $\mathrm{Al}(\mathrm{O}) \mathrm{N}$ thin films by tuning of the local structure, electronic structure and film thickness. Analysis of the electronic structure by electron energy loss spectroscopy (EELS) at the Ce-M4,5, Al- $\mathrm{L}_{2,3}$, $\mathrm{O}-\mathrm{K}$ and $\mathrm{N}-\mathrm{K}$ edges and photoluminescence spectroscopies highlight the essential role of oxygen and post-deposition annealing in changing the valence state of $\mathrm{Ce}$ ions from $\mathrm{Ce}^{4+}$ (optically inactive) to $\mathrm{Ce}^{3+}$ (optically active) as well as the local field around $\mathrm{Ce}^{3+}$ and, finally, in activating excitation pathways through generation of specific defect complexes in the oxynitride matrix.
\end{abstract}




\section{Introduction}

Generation of white light attracts great attention since the beginning of the development of solid state lighting applications, e.g. light emitting diodes (LEDs). In recent years, progress has been achieved in white light LEDs, which is considered as the next generation solid state lighting systems. Basically, white light can be obtained from combination of the three RBG colors (Red, Blue, Green) or mixing blue with yellow color. ${ }^{1}$ However, from technological point of view, generating white light is facing some obstacles that can be summarized as follows: first, fabrication of high quality of host crystals is needed, second, color mixing with different phosphors (blue-green-red or blue-yellow phosphors) with high color quality is necessary and, third, high thermal stability under high power and long time working is desired. Most of these issues can be addressed by generating white light without the use of phosphor color mixing to avoid the mixing problems as well as by using a host material with crystalline structure and exhibiting high thermal conductivity in order to dissipate the unwanted heat resulting from the high power and long time operation. In this direction, aluminum nitride attracts particular attention owing to its crystalline structure and luminescence-related properties. It exhibits wide bandgap, large thermal stability, high thermal conductivity as well as compatibility with silicon optoelectronic technology. ${ }^{2} \mathrm{AlN}$ has therefore become an ideal candidate for solid state applications and is used as a host material for integrating the luminescence of rare earth (RE) ions into solid state lightening applications. Most of RE-doped AlN have been reported with light emission covering wide range of light spectrum, depending on the RE, from UV (Gd), ${ }^{3}$ blue $(\mathrm{Ce}, \mathrm{Eu}, \mathrm{Tm}),{ }^{4-5}$ green (Tb), ${ }^{6}$ yellow (Dy), ${ }^{7}$ red $(\mathrm{Sm}, \mathrm{Eu})^{7}$ to IR $(\mathrm{Yb}, \mathrm{Nd}) .{ }^{8-9}$ Among $\mathrm{RE}$ ions, $\mathrm{Ce}^{3+}$ is of particular interest due to its fast and efficient luminescence in UV-blue regions. ${ }^{10-11}$ In addition, $\mathrm{Ce}^{3+}$ has only one electron in $4 f$ state that results in the excited electron to $5 d$ level becomes unshielded from the host crystal field effect. As a consequence, the spectral properties are 
strongly affected by the surrounding environment. ${ }^{10,12}$ Therefore, the luminescence properties of $\mathrm{Ce}^{3+}$ can be manipulated by modifying the local surrounding composition resulting in the ability to adjust the emission color to meet the desired application. The effective blue part of a composite white spectrum is located from $440 \mathrm{~nm}$ to $500 \mathrm{~nm} \cdot{ }^{13-14}$ Thus, controlling the emission color of $\mathrm{Ce}^{3+}$ to emit in the $\mathrm{UV}$, blue, ${ }^{15}$ green $^{16}$ to yellow ${ }^{17-18}$, is of great importance for getting high color quality of white light. Furthermore, the possibility to tune the emission color of $\mathrm{Ce}^{3+}$ using the same host material would open the door to produce white light without the need to mix different materials with several phosphors. Recently, a broad band emission from Ce-doped AlN bulk material has been reported ${ }^{19}$, but a thin film structure on silicon substrate is required for integration with chip technology and experimental evidence of $\mathrm{Ce}$ oxidation state and its local environment on the emission of Ce-doped AIN is still missing. Furthermore, deep structure analyses correlated with optical measurements are essential to draw a complete picture in this regard. Besides, oxygen is considered as native impurity inside AlN that can't be completely avoided due to its high affinity to interact with $\mathrm{Al}$ even at very low concentration level, but its influence on the luminescence of Ce-doped AlN material has been overlooked in most previous reports. ${ }^{20-22}$ In the present study we address the essential roles of oxygen, thermal annealing and tailoring of the defect chemistry of the host matrix in manipulating the optical emission in Ce-doped AlN single layer from blue, to green, to orange and finally white. The relation between the electronic, local structures and optical properties is unraveled.

\section{Experimental section}

Ce-doped AlN thin films have been prepared by RF magnetron sputtering at high base vacuum in order to minimize the background concentration of oxygen to less than 2 at.\% inside the prepared films. The influence of oxygen has been also examined by intentionally 
inserting oxygen during the growth process with different flow rates to obtain 7, 13 and 60 at.\% of oxygen inside the aluminum oxynitride samples. So, during the study three Ce-doped oxynitride samples, with film thickness $200 \mathrm{~nm}$, namely $\mathrm{Ce}-\mathrm{Al}(\mathrm{O}) \mathrm{N} \_2 \%, \mathrm{Ce}-\mathrm{Al}(\mathrm{O}) \mathrm{N} \_7 \%$ and Ce-Al(O)N_13\% with different oxygen contents $(2 \%, 7 \%, 13 \%$; respectively) and the oxide counterpart Ce- $\mathrm{Al}_{2} \mathrm{O}_{3}$ are investigated. Undoped $\mathrm{Al}(\mathrm{O}) \mathrm{N} \_7 \%$ and $\mathrm{Al}_{2} \mathrm{O}_{3}$, with film thickness $200 \mathrm{~nm}$, were prepared for comparison purposes. Finally, two thick samples, $9 \mu \mathrm{m}$, of undoped $\mathrm{Al}(\mathrm{O}) \mathrm{N} \_7 \%$ and $\mathrm{Ce}-\mathrm{doped} \mathrm{Al}(\mathrm{O}) \mathrm{N}_{-}$7\% were synthesized to examine the influence of film thickness. Ce- $\mathrm{Al}(\mathrm{O}) \mathrm{N}$ thin films were deposited using $\mathrm{RF}$ (Dressler, CESAR RF power generator) balanced reactive magnetron sputtering. A high vacuum pressure of $2 \times 10^{-}$ ${ }^{8}$ torr was obtained by using a turbo molecular pump (BOC EDWARDS EXT 255HI) coupled to a mechanical primary pump. An aluminum disk $(99.99 \%$ purity, neyco vacuum \& materials) of 2 inch diameter was used as a target that incorporates a thin bar of metallic $\mathrm{Ce}$ (99.9\% purity, neyco vacuum \& materials) with appropriate relative $\mathrm{Ce} / \mathrm{Al}$ surface areas of about 0.027 in order to obtain 1 at.\% of $\mathrm{Ce}$ in the deposited films. Constant gas composition of Ar and nitrogen with $65 \%$ nitrogen was controlled by adjusting the argon and nitrogen gas flow rates and keeping the total pressure $(0.7$ mtorr $)$ constant using an MKS mass flow controller. For $\mathrm{Ce}-\mathrm{Al}(\mathrm{O}) \mathrm{N}$ sample contains $2 \%$ of oxygen, a high background vacuum pressure was set at $2 \times 10^{-8}$ torr. For samples of higher oxygen content, a flow rate of oxygen was applied using all-metal gas regulating valve allowing a fine control of the oxygen partial pressure in the 0.1 to $50 \times 10^{-6}$ torr range. This led to 7,13 and 60 at.\% of oxygen in our samples. The film composition has been measured using Energy-dispersive X-ray (EDX) spectroscopy embedded in a transmission electron microscope (TEM).The EDX data were calibrated using RBS measurements performed on samples reported in. ${ }^{23}$ The partial pressure of oxygen has been measured using in situ mass spectrometry. Silicon (100) substrates have been ultrasonically cleaned in ethanol and fixed at $5 \mathrm{~cm}$ distance from the $\mathrm{Al}$ target, facing the 
target axis. The deposition time was adjusted for each deposition condition to reach a thickness close to $200 \mathrm{~nm}$ and $9 \mu \mathrm{m}$ as monitored using in-situ laser interferential reflectometry. More details can be found in ref. ${ }^{24}$ The samples underwent a post-deposition rapid thermal annealing (RTA) at $1000{ }^{\circ} \mathrm{C}$ in forming gas $(\mathrm{FG})\left(\mathrm{N}_{2} / \mathrm{H}_{2} \%=90 / 10\right)$ for 5 minutes. Details of the microstructure were investigated by transmission electron microscopy (TEM, JEOL ARM 200-Cold FEG fitted with a GIF Quantum ER). Electron Energy Loss Spectroscopy (EELS) coupled to the TEM instrument has been used for investigating the oxidation states of Ce ions. For the acquisition of EEL spectra, an accelerating voltage of 200 $\mathrm{kV}$, an emission current of $15 \mu \mathrm{A}$ and an energy dispersion of $0.05 \mathrm{eV} / \mathrm{ch}$ were employed. All spectra were recorded in image mode, with an energy resolution of $0.55 \mathrm{eV}$ defined by the full width at half maximum (FWHM) of the zero loss peak. The steady state PL experiments were performed at room temperature. Samples were excited by the $325 \mathrm{~nm}$ line of $\mathrm{He}-\mathrm{Cd}$ laser. For PLE spectroscopy, samples were excited by a xenon arc lamp source. PL emission was analyzed by a cooled silicon-based CCD camera.

\section{Results and discussion}

\section{1- Microstructure}

To investigate the influence of oxygen on the microstructure and crystallinity of $\mathrm{Al}(\mathrm{O}) \mathrm{N}$ matrix, transmission electron microscopy $(\mathrm{TEM})$ of $\mathrm{Ce}-\mathrm{Al}(\mathrm{O}) \mathrm{N} \_2 \%$ and $\mathrm{Ce}-\mathrm{Al}(\mathrm{O}) \mathrm{N} \_7 \%$ films are examined. Figure 1a, b shows the HRTEM images with corresponding SAED pattern for these two samples. Both samples are polycrystalline with columnar microstructure. The SAED patterns evidence better orientation of the c-axis along the growth direction in the as-deposited $\mathrm{Ce}-\mathrm{Al}(\mathrm{O}) \mathrm{N} \_2 \%\left(\mathrm{Ce}-\mathrm{Al}(\mathrm{O}) \mathrm{N} \_2 \% \_\mathrm{As}\right)$ sample than in the as-deposited Ce$\mathrm{Al}(\mathrm{O}) \mathrm{N} \_7 \%\left(\mathrm{Ce}-\mathrm{Al}(\mathrm{O}) \mathrm{N} \_7 \% \_\mathrm{As}\right)$. Indeed, scatter diffraction points belonging to different 
crystallographic are observed in the SAED of $\mathrm{Ce}-\mathrm{Al}(\mathrm{O}) \mathrm{N} \_7 \%$ _As orientations indicating the absence of pronounced preferential orientation in this sample. The HRTEM images of both samples show local structural defects indicated by the red arrows, likely induced by the introduction of dopant atoms. More precisely, the HRTEM of Ce-Al(O)N_2\%_As sample shows some random local structure disorder that may be due to incorporation of Ce ions. This local disorder in the microstructure leads to significant microstrain, as reported in. ${ }^{23}$ However, in both cases, the crystallites are mostly oriented along the [002] direction of $\mathrm{Al}(\mathrm{O}) \mathrm{N}$ (see, the direction of the white arrows) as also evidenced by the intense localized spots in the diffraction pattern, while the HRTEM image of $\mathrm{Ce}-\mathrm{Al}(\mathrm{O}) \mathrm{N} \_7 \%$ As sample reveals a higher density of structural defects. In particular, some regions appear with amorphous-like structure (indicated by the red arrows Figure 1b) and lateral discontinuity in the atomic arrangements near the grain boundaries (array of white arrows). In addition, crystallites present different crystalline orientations along the growth direction resulting in the presence of partial rings in the SAED pattern. Such strong structural modifications have been generally observed in all our oxynitride samples with oxygen concentration higher than $2 \%$.

Despite some of these defects could be attributed to the presence of Ce ions due to the large ionic radius of $\mathrm{Ce}$ that induces microstrain in the crystal lattice, we mainly ascribe these structural modifications to oxygen incorporation. This is consistent with the reported strong modification induced by oxygen in AIN microstructure in several works. ${ }^{25-27}$ 

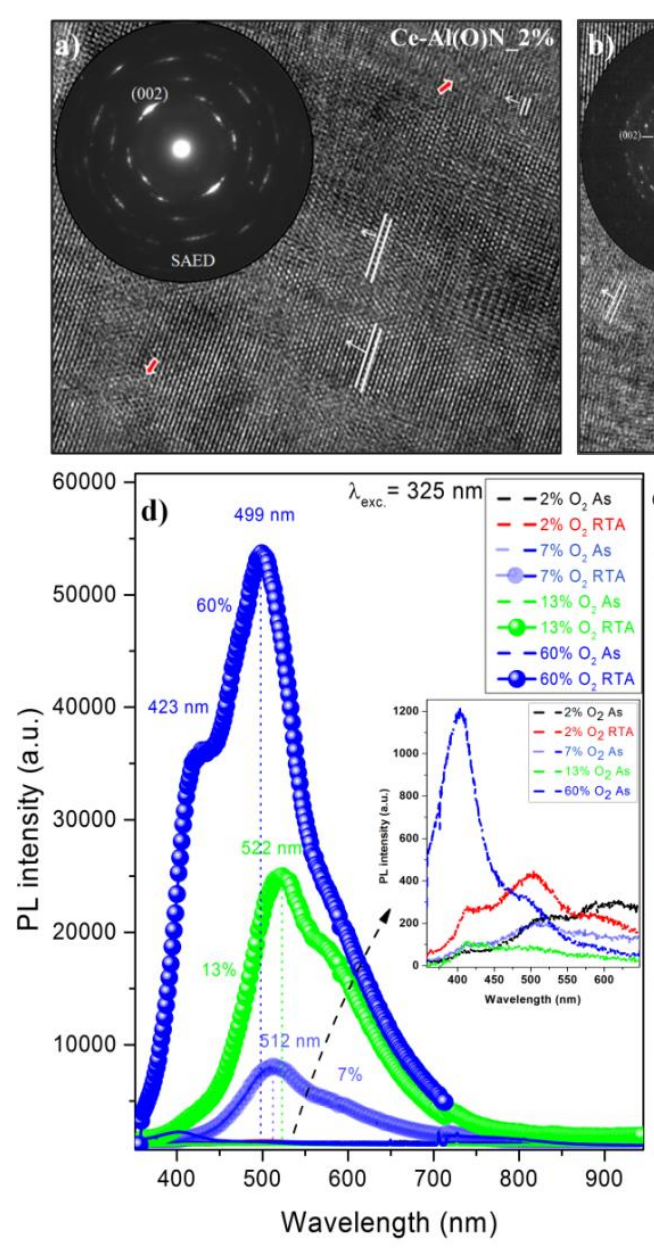
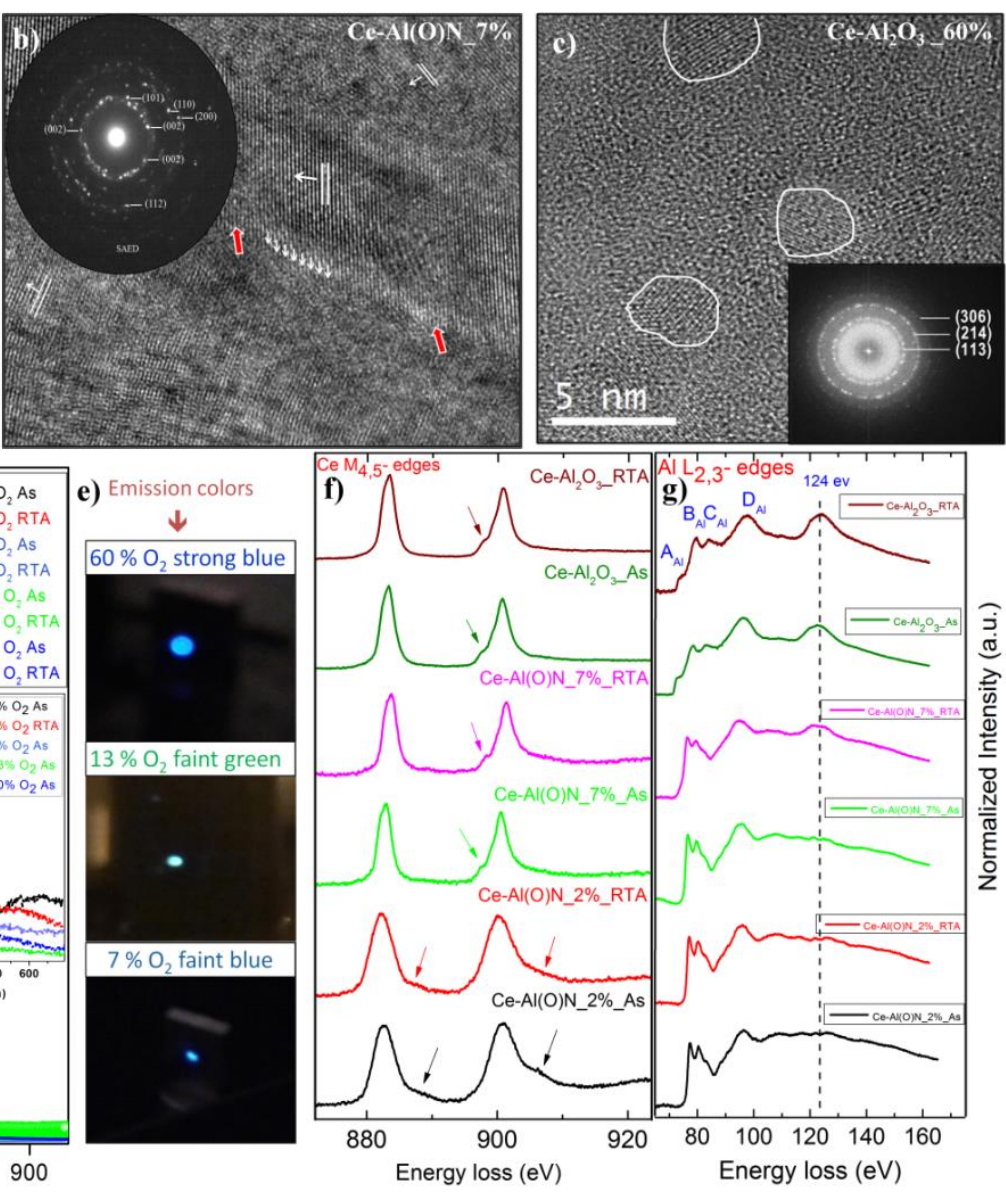

Figure1.(a, b, c) HRTEM images and the corresponding SAED patterns of Ce-Al(O)N_2\%_As,Ce$\mathrm{Al}(\mathrm{O}) \mathrm{N} \_7 \%$ _As and $\mathrm{Ce}-\mathrm{Al}_{2} \mathrm{O}_{3} \_\mathrm{As}$. d) PL spectra of as-deposited and annealed $\mathrm{Ce}-\mathrm{Al}(\mathrm{O}) \mathrm{N}$ at oxygen contents of $2 \%, 7 \%, 13 \%$ and $\mathrm{Ce}_{-} \mathrm{Al}_{2} \mathrm{O}_{3}-60 \%$. Inset fig. is the magnification of the weak PL signals of as-deposited samples and annealed sample of $2 \%$ oxygen content. e) The corresponding eye observed emission photos of annealed $\mathrm{Ce}-\mathrm{Al}(\mathrm{O}) \mathrm{N}$ at oxygen contents of $7 \%, 13 \%$ and $\mathrm{Ce}_{-}-\mathrm{Al}_{2} \mathrm{O}_{3}$. (f, g) EELS at $\mathrm{Ce}_{4,5}$-edges and $\mathrm{Al} \mathrm{L}_{3,2^{-}}$ edges; respectively, of as-deposited and annealed $1 \% \mathrm{Ce}-\mathrm{Al}(\mathrm{O}) \mathrm{N}_{-} 2 \%, 1 \% \mathrm{Ce}-\mathrm{Al}(\mathrm{O}) \mathrm{N}_{-} 7 \%$, and $\mathrm{Ce}-\mathrm{Al}_{2} \mathrm{O}_{3}$ samples. The arrows are to guide the reader for the peak shoulders.

This influence of oxygen on the microstructure appears strongly in sample contains high oxygen concentration about $60 \%$. This sample has an $\mathrm{O} / \mathrm{Al}$ ratio very close to $\mathrm{Al}_{2} \mathrm{O}_{3}$ and its microstructure consists in nanocrystalline $\mathrm{Al}_{2} \mathrm{O}_{3}$ : The HRTEM image displays very small 
nanocrystals of $\mathrm{Al}_{2} \mathrm{O}_{3}$ that can be observed by the highlighted lattice planes and identified to $\mathrm{Al}_{2} \mathrm{O}_{3}$ by indexing the FFT (JCPDS 46-1212), as shown in Figure (1c).

\section{2- Photoluminescence (PL) response}

\section{a) Role of oxygen on the valence state of Cerium}

For investigating the photoluminescence (PL) response, small parts of the previous two samples underwent thermal activation via rapid thermal annealing (RTA) in forming gas (FG) at $1000{ }^{\circ} \mathbf{C} / 5 \mathrm{~min}$. This was found necessary to enhance the optical activity of RE ions. ${ }^{28}$ Then the PL of as-deposited, Ce-Al(O)N_2\%_As and Ce-Al(O)N_7\%_As, and annealed, Ce$\mathrm{Al}(\mathrm{O}) \mathrm{N} \_2 \% \_\mathrm{RTA}$ and $\mathrm{Ce}-\mathrm{Al}(\mathrm{O}) \mathrm{N} \_7 \%$ RTA, samples has been carried out using an excitation wavelength of $325 \mathrm{~nm}$, Figure 1d. Only the annealed sample, Ce$\mathrm{Al}(\mathrm{O}) \mathrm{N} \_7 \%$ RTA,shows a strong PL signal. This signal is broad with a maximum centered at $512 \mathrm{~nm}$ and full width at half maximum about $100 \mathrm{~nm}$. These spectral features are characteristic of the optical response of the $5 d-4 f$ transition in $\mathrm{Ce}^{3+}$. It is known that $\mathrm{Ce}$ can be found in two oxidation states, $\mathrm{Ce}^{4+}$ and $\mathrm{Ce}^{3+}$. The former is optically inactive due to absence of free electrons in its outer shell orbital $4 f$ unlike the later, $\mathrm{Ce}^{3+}$, which contains one electron in the $4 f$ level. The $4 f-5 d$ electronic transition of $\mathrm{Ce}^{3+}$ results in optical emission. Hence, one can assume that the sample, which emits strong PL intensity, contains Ce ions with oxidation state $3+$, unlike the other samples of weak PL which likely have $\mathrm{Ce}^{4+}$. To justify this assumption and to probe the oxidation state of Ce ions, EELS measurements have been performed for all samples. It is worth to mention that the EELS spectrum of $\left(\mathrm{Ce}^{4+}\right)$ can be characterized by a shoulder, absent in $\mathrm{Ce}^{3+}$, located at $5 \mathrm{eV}$ (due to the excitation of $4 f^{0}$ initial states) above the fundamental two peaks of $\mathrm{M}_{4}$ (due to $3 d_{3 / 2}-4 f_{5 / 2}$ transitions) and $\mathrm{M}_{5}$ (due to $3 d_{5 / 2}-4 f_{7 / 2}$ transitions). In contrast, in the case of $\mathrm{Ce}^{3+} \mathrm{a}$ pre-shoulder appears in the $\mathrm{M}_{4}$ peak. ${ }^{23 \text {, }}$

29 The corresponding EELS spectra probing $\mathrm{Ce}$ M-edges in $\mathrm{Ce}-\mathrm{Al}(\mathrm{O}) \mathrm{N} \_2 \%$ and $\mathrm{Ce}-$ $\mathrm{Al}(\mathrm{O}) \mathrm{N} \_7 \%$ as-deposited and annealed samples are presented in Figure 1f. It is observed that 
the EELS signals of $\mathrm{Ce}-\mathrm{Al}(\mathrm{O}) \mathrm{N} \_2 \%$ before and after annealing are close to the signature of $\mathrm{Ce}^{4+}$, which means that the predominant oxidation state of $\mathrm{Ce}$ in these samples is the optically inactive $\mathrm{Ce}^{4+}$. This is consistent with the very weak PL signal from these samples. In opposite, EELS spectra of Ce-Al(O)N_7\%_As and Ce-Al(O)N_7\%_RTA samples, containing more oxygen, exhibit the nature of optically active $\mathrm{Ce}^{3+}$ ions with the pre-shoulder in $\mathrm{M}_{4}$ peak reported elsewhere. ${ }^{29}$ This suggests that oxygen plays a role in changing the majority of valence state of Ce from +4 to +3 as proposed in our recent study. ${ }^{23}$

Hence, one can expect that higher oxygen concentration will affect the PL response. Thus, emphasizing on the role of oxygen on the PL, another oxynitride sample with higher concentration of oxygen about $13 \%$ was prepared and annealed in $\mathrm{FG}(1 \% \mathrm{Ce}-$ Al(O)N_13\%_RTA). The PL signal of this sample is shown in Figure1d along with those of $\mathrm{Ce}-\mathrm{Al}(\mathrm{O}) \mathrm{N}_{7} 7$ and $\mathrm{Ce}-\mathrm{Al}_{2} \mathrm{O}_{3}$. Different spectral intensities, peak positions and shapes are obtained depending on the oxygen content. As the oxygen concentration increases the PL intensity increases. This can be explained by two combined effects. The first is the increase in the number of $\mathrm{Ce}^{4+}$ converted into $\mathrm{Ce}^{3+}$ ions with oxygen incorporation. The second is related to the local oxide environment, which likely offers a better surrounding to cerium for efficient excitation and emission pathways. Consistently, it has been found that the optical emission of RE in semiconductors can be significantly enhanced when it is surrounded with strong electronegative ligand field. ${ }^{30}$ For instance, incorporating oxygen in Er-doped GaN and AlN results in increasing the luminescence efficiency, which is ascribed to the conversion of the local bonds into more ionic states. ${ }^{31}$ In this line, a similar effect of oxygen has been reported in Ce-doped silicon nitride matrix, $\mathrm{Si}_{3} \mathrm{~N}_{4}$. The authors found that presence of oxygen is crucial for $\mathrm{Ce}^{3+}$ emission. ${ }^{32-33}$ This pushed the research direction to Ce-doped silicon oxynitride matrix as an intermediate solution between silicon nitride and oxide. This combines the advantages of oxygen for PL enhancement and overcomes the drawbacks of the limit 
solubility of $\mathrm{Ce}$ in silicon oxide matrix despite it exhibits stronger PL compared to the silicon oxynitride counterpart of higher solubility. ${ }^{33}$ Although the reason behind the very weak emission in $\mathrm{Si}_{3} \mathrm{~N}_{4}$ is not completely elaborated, the presence of optically inactive $\mathrm{Ce}^{4+}$ can be considered as discussed above for AlN. It is worth to mention that the presence of $\mathrm{Ce}^{4+}$ in AlN (or similarly in $\mathrm{Si}_{3} \mathrm{~N}_{4}$ ) can be attributed to presence of a large number of $\mathrm{N}^{3-}$ ions surrounding it in the crystal lattice. In more details, Landrum, G.A., ${ }^{34}$ demonstrated that $\mathrm{Ce}^{4+}$ exists even in $\mathrm{CeN}$ that "formally" contains $\mathrm{Ce}^{3+}$. Their findings were attributed to the substantial $d$ character of the remaining electron in $\mathrm{Ce}^{3+}$ that delocalizes in the direction of the Ce-Ce interaction. In addition the lattice structure of w-AlN which consists of tetrahedron units likely more adapted to the tetra-valent state of Ce than to the tri-valent one. Moreover the smaller ionic size of $\mathrm{Ce}^{4+}$ than $\mathrm{Ce}^{3+}$ might favor less structural disturbance during the preparation of AlN. In contrast, in Ce-doped oxynitride matrices, presence of oxygen "as electron donor" pushes to reduce $\mathrm{Ce}^{4+}$ into $\mathrm{Ce}^{3+}$ and simultaneously alters/relaxes the lattice structure (by substituting $\mathrm{N}$-sites and forming Al-vacancies) to be adapted for the larger ionic size of Ce (III). This will break the local structure and electronic symmetries around Ce ions by altering the bonding system either by forming $\mathrm{Al}-\mathrm{O}$ or by formation of $\mathrm{V}_{\mathrm{Al}}$, as will be shown later.

In addition, a shift in the PL peak positions is observed with the content of oxygen. Interestingly, this shift is sufficient to change the observed emission color from faint blue to faint green, then to strong blue as seen the photos of Figure 1e. The change in color occurs because the PL peaks lay between two adjacent color regions (end of blue at $500 \mathrm{~nm}$ and beginning of green at $522 \mathrm{~nm}$ ). This shift originates from the modification of the local environment around unshielded $5 d$ electrons of $\mathrm{Ce}^{3+}$ ions as the $\mathrm{O} / \mathrm{N}$ ratio is changed. More precisely, changing the local coordination ratio between oxygen and nitrogen around $\mathrm{Ce}^{3+}$ modifies the energy position of the excited $5 d$-level of Ce. ${ }^{35}$ In addition, the difference in the 
formal charge between $\mathrm{N}^{3-}$ and $\mathrm{O}^{2-}$ ions as well as the difference in their electronegativity values (3.04 for $\mathrm{N}$ and 3.44 for $\mathrm{O}$ ) induces a significant modification in the local fields that surround the excited $5 d$-level of $\mathrm{Ce}^{3+}$ when the $\mathrm{O} / \mathrm{N}$ ratio is changed. This is considered as a unique character of $\mathrm{Ce}^{3+}$ over all the other $\mathrm{RE}^{3+} \cdot 35$ To the best of our knowledge this is the first demonstration of such effect in Ce-doped AlN.

The PL signal of Ce in aluminum oxide sample shows an additional peak around $423 \mathrm{~nm}$ generally attributed to a second lattice occupancy by Ce ions. It is well established that for $\mathrm{Ce}^{3+}$ located in a single lattice site, the asymmetry in the emission of $\mathrm{Ce}^{3+}$ corresponds to the transitions from the lowest $5 d$ excited state to the ${ }^{2} \mathrm{~F}_{5 / 2}$ and ${ }^{2} \mathrm{~F}_{7 / 2}$ spin-orbit split of $4 f$ ground states. The reported theoretical value of the energy separation of this spin-orbit splitting is accounted around $2000 \mathrm{~cm}^{-1}$. This can explain the origin of the small hump in the PL spectra at $~ 570 \mathrm{~nm}$ with energy separation values $1988 \mathrm{~cm}^{-1}, 1614 \mathrm{~cm}^{-1}$, and $2497 \mathrm{~cm}^{-1}$ from the PL peaks located at $512 \mathrm{~nm}, 522 \mathrm{~nm}$, and $499 \mathrm{~nm}$ in samples containing of 7\%, 13\%, and 60\% oxygen; respectively. Such deviation around the theoretical value is considered acceptable. ${ }^{36}$ On the contrary the energy separation of $3600 \mathrm{~cm}^{-1}$ between the two peaks, $423 \mathrm{~nm}$ and 499 $\mathrm{nm}$, in $\mathrm{Ce}-\mathrm{Al}_{2} \mathrm{O}_{3}$ is too large to be accounted to the spin-orbit splitting. Thus, the emission band at $423 \mathrm{~nm}$ should come from $\mathrm{Ce}^{3+}$ in another site in the host lattice. ${ }^{37}$

Surprisingly, only the annealed samples, except Ce-Al(O)N_2\%_RTA, exhibit strong PL despite the as deposited $\mathrm{Ce}-\mathrm{Al}(\mathrm{O}) \mathrm{N} \_7 \%, \mathrm{Ce}-\mathrm{Al}(\mathrm{O}) \mathrm{N} \_13 \%$ and $\mathrm{Ce}-\mathrm{Al}_{2} \mathrm{O}_{3}$ also contain a majority of $\mathrm{Ce}^{3+}$ state. This reveals the presence of $\mathrm{Ce}^{3+}$ is necessary but not sufficient to activate the PL. It must be accompanied by a post-deposition annealing step.

\section{b) Role of post-deposition annealing}


It is believed that annealing can reduce the density of non-radiative defects acting as PL quenching centers. ${ }^{28}$ Moreover, annealing at high temperature can provide sufficient energy to initiate new local bonds between oxygen with $\mathrm{Al}$ and/or $\mathrm{Ce}$ atoms. In order to gain more information about the influence of annealing on the bonding structure, the electronic structure at the $\mathrm{Al} \mathrm{L} \mathrm{L}_{2,3}$-edges was measured using EELS, Figure 1g. Four peak features in the range 73$100 \mathrm{eV}$ are common in $\mathrm{Ce}-\mathrm{Al}(\mathrm{O}) \mathrm{N}$ and $\mathrm{Ce}-\mathrm{Al}_{2} \mathrm{O}_{3}$ samples and similar to the $\mathrm{Al} \mathrm{L}_{2,3}$ edges reported in. ${ }^{38}$ They were attributed to the antibonding and bonding interactions of $\mathrm{Al}$ atom with the surrounding. The first triple peak features $\mathrm{A}_{\mathrm{Al}}, \mathrm{B}_{\mathrm{Al}}, \mathrm{C}_{\mathrm{Al}}$ are commonly composed of the antibonding and bonding interactions of $\mathrm{Al} 3$ s-anion $(\mathrm{N}$ or $\mathrm{O})$ and $\mathrm{Al} 3 \mathrm{~d}$-anion $(\mathrm{N}$ or $\mathrm{O})$; respectively. While the feature at $\mathrm{D}_{\mathrm{Al}}$ is due to $\mathrm{Al}-\mathrm{Al}$ antibonding. ${ }^{39}$ Main changes in the EELS spectra triggered by deposition and annealing conditions are observed at contributions around $80 \mathrm{eV}$ and $124 \mathrm{eV}$. The shape of the $80 \mathrm{eV}$ band, consisting of three sub-bands, is the same for $\mathrm{Al}(\mathrm{O}) \mathrm{N}$ hosts at $2 \%$ and $7 \%$ of oxygen, while it is different in the case of $\mathrm{Al}_{2} \mathrm{O}_{3}$. Hence, this band can be used as a sign to the general phase transition from $\mathrm{Al}(\mathrm{O}) \mathrm{N}$ to $\mathrm{Al}_{2} \mathrm{O}_{3}$, as reported elsewhere. ${ }^{40}$ The band at $124 \mathrm{eV}$ is practically absent in $\mathrm{Al}(\mathrm{O}) \mathrm{N} \_2 \%$ host and asdeposited $\mathrm{Al}(\mathrm{O}) \mathrm{N} \_7 \%$ while it is present in $\mathrm{Al}_{2} \mathrm{O}_{3}$ and in annealed $\mathrm{Al}(\mathrm{O}) \mathrm{N} \_7 \%$, but weaker in the latter case. This band is a clear feature of the electronic structure of $\mathrm{Al}_{2} \mathrm{O}_{3} .{ }^{40}$ This infers that annealed $\mathrm{Al}(\mathrm{O}) \mathrm{N} \_7 \%$ exhibits some $\mathrm{Al}_{2} \mathrm{O}_{3}$ characters even though its general crystal structure is that of wurtzite AlN. We can interpret this result by considering the local formation of $\mathrm{Al}-\mathrm{O}$ bonds in annealed $\mathrm{Al}(\mathrm{O}) \mathrm{N}$.

\section{3- Origin of the photoluminescence}

I) From local chemistry point of view

From the above, it is realized that presence of $\mathrm{Ce}^{3+}$ along with thermal annealing are essential for obtaining high PL response. However, the emission from $\mathrm{Ce}^{3+}$ can originate from different types of $\mathrm{Ce}^{3+}$ centers. Three different Ce-emitting centers can be considered; namely Ce-Ce 
clustering centers, $\mathrm{Ce}$ oxides involving $\mathrm{Ce}^{3+}$, and $\mathrm{Ce}^{3+}$ isolated in $\mathrm{Al}(\mathrm{O}) \mathrm{N}$ matrix. ${ }^{33}$ The first type of centers is formed when two or more Ce ions are very close and lead to cluster formation (dimer, trimer...etc), which could favor the formation of optically active $\mathrm{Ce}^{3+}$. The formation of this RE pairs in crystals is attributed to large $\mathrm{RE}^{3+}$ ions that induce distortion and subsequently the formation of pairs. ${ }^{41}$ Though no observable signs for such cluster formation have been found in the HRTEM images and SAED patterns in our samples. Ce oxide compounds involving $\mathrm{Ce}^{3+}$ can be especially formed after annealing at high temperature (e.g. $\mathrm{Ce}_{2} \mathrm{O}_{3}, \mathrm{CeO}_{2}$ assisted by oxygen vacancy ${ }^{42}$ or $\left.\mathrm{Ce}_{6} \mathrm{O}_{11}{ }^{43} \ldots ..\right)$. No signal related to $\mathrm{Ce}$ oxide species has been found in the SAED patterns of the prepared samples, see Figure1 ( $a, b$ and c). For further confirming the absence of Ce oxide compounds, EELS at the O-K edge has been collected for our oxynitride $\left(\mathrm{Ce}-\mathrm{Al}(\mathrm{O}) \mathrm{N} \_7 \%\right.$. RTA $)$ and $\mathrm{Al}_{2} \mathrm{O}_{3}$ RTA samples and compared with the $\mathrm{O}-\mathrm{K}$ edge collected from $\mathrm{CeO}_{2}$ powder. 

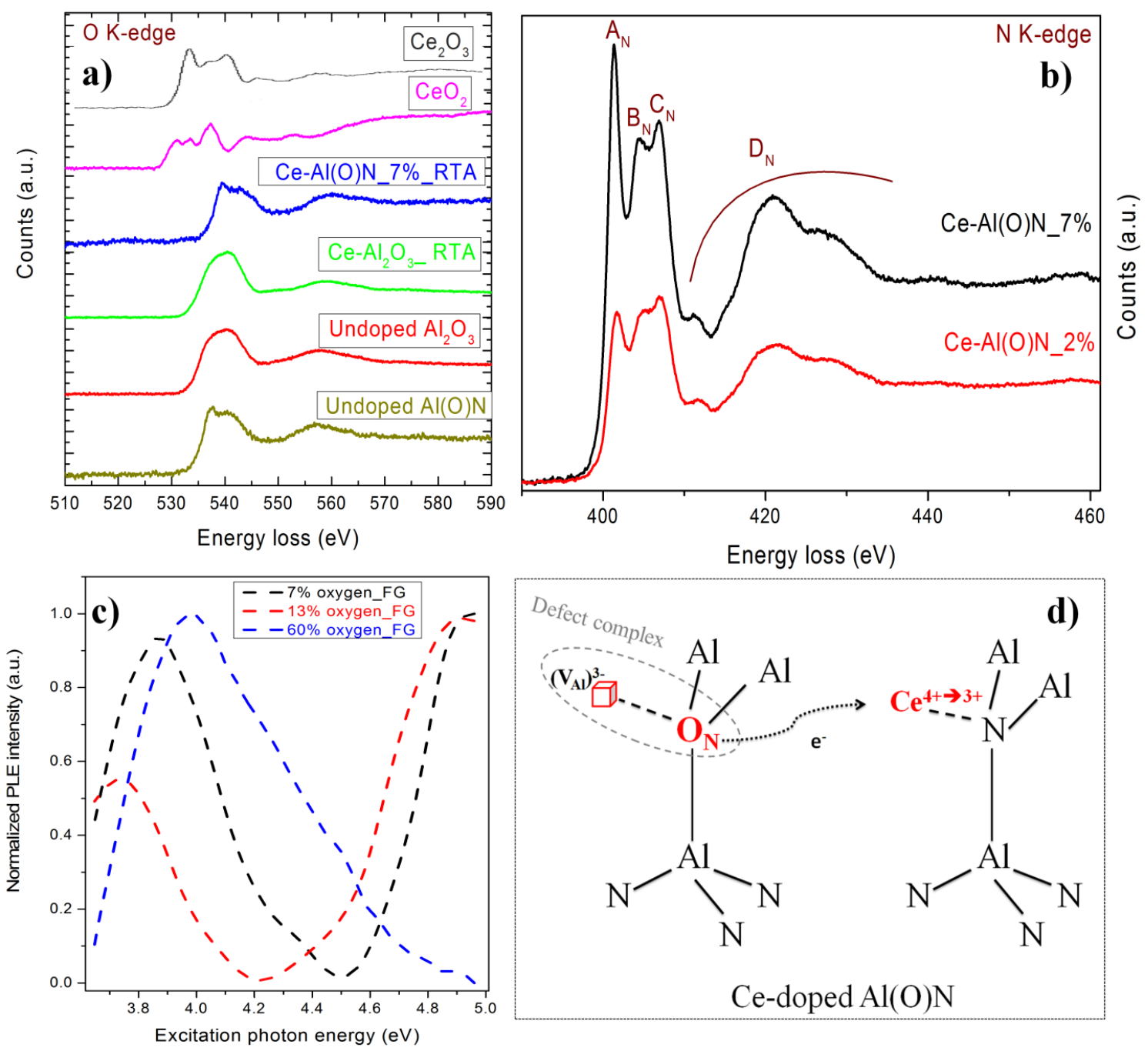

Figure 2.(a) EELS at the $\mathrm{O}$ K-edges of $\mathrm{Ce}-\mathrm{Al}(\mathrm{O}) \mathrm{N} \_7 \%$ RTA, Ce- $\mathrm{Al}_{2} \mathrm{O}_{3} \_\mathrm{RTA}$, undoped $\mathrm{Al}(\mathrm{O}) \mathrm{N} \_7 \%$, undoped $\mathrm{Al}_{2} \mathrm{O}_{3}$ and $\mathrm{CeO}_{2}$ powder from the present study and $\mathrm{Ce}_{2} \mathrm{O}_{3}$ from ref. ${ }^{44}$ b) EELS at the $\mathrm{N}$ K-edges of Ce$\mathrm{Al}(\mathrm{O}) \mathrm{N} \_2 \% \_\mathrm{RTA}$ and $\left.\mathrm{Ce}-\mathrm{Al}(\mathrm{O}) \mathrm{N} \_7 \% \_\mathrm{RTA} . \mathrm{c}\right)$ PLE spectra of $\mathrm{Ce}-\mathrm{Al}(\mathrm{O}) \mathrm{N} \_7 \%$ RTA, Ce-Al(O)N_13\%_RTA and $\mathrm{Ce}-\mathrm{Al}_{2} \mathrm{O}_{3}$ RTA samples. d) Schematic representation of oxygen, aluminum vacancy and Ce related defects in AlN.

Figure2a shows that the shape of $\mathrm{O}-\mathrm{K}$ edge in $\mathrm{Ce}-\mathrm{Al}(\mathrm{O}) \mathrm{N}_{-} 7 \%$ is similar to that of $\mathrm{Ce}-\mathrm{Al}_{2} \mathrm{O}_{3}$ and both differ from the lineshapes of $\mathrm{CeO}_{2}$ powder and $\mathrm{Ce}_{2} \mathrm{O}_{3}$. Hence, our samples do not contain detectable amounts of $\mathrm{CeO}_{2}$ or $\mathrm{Ce}_{2} \mathrm{O}_{3}$, even in the sample with a large amount of oxygen concentration $(60 \%)$. The $\mathrm{O}$ K-edge ofCe- $\mathrm{Al}_{2} \mathrm{O}_{3}$ is characterized by two broad contributions around $540 \mathrm{eV}$ and $560 \mathrm{eV}$. They can be assigned to electron transitions to the unoccupied states in the conduction band derived from O-2p states mixed with $\mathrm{Al}$ e $\left(\mathrm{t}_{2 \mathrm{~g}}\right)$ and 
Al $t_{2}\left(\mathrm{e}_{\mathrm{g}}\right)$ states (for $540 \mathrm{eV}$ ) and with Al 3s- and Al 3p-states (for $560 \mathrm{eV}$ ). ${ }^{45}$ Similar lineshape is obtained for $\mathrm{Ce}-\mathrm{Al}(\mathrm{O}) \mathrm{N}_{-} 7$, except the first band that shows an additional sharp feature. This is attributed to the interaction of the surrounding metal ( $\mathrm{Al}$ in our case) with oxygen and nitrogen atoms in oxynitride matrices. As oxygen substitutes nitrogen the local symmetry is changed around $\mathrm{Al}$ atoms, resulting in splitting in its $\mathrm{t}_{2 \mathrm{~g}}$ and $\mathrm{e}_{\mathrm{g}}$ states. ${ }^{45-47} \mathrm{To}$ ensure that $\mathrm{Ce}$ has no influence on such splitting, the $\mathrm{O}$ k-edge spectra was collected for undoped $\mathrm{Al}(\mathrm{O}) \mathrm{N}$ and $\mathrm{Al}$-oxide samples, Figure 2a. It can be observed that the $\mathrm{O}$ K-edges of undoped samples are consistent with the Ce-doped samples, confirming the origin of the sharp contribution. For better probing the local environment, the $\mathrm{N}$ k-edge of $\mathrm{Ce}-\mathrm{Al}(\mathrm{O}) \mathrm{N} \_2 \%$ and $\mathrm{Ce}-\mathrm{Al}(\mathrm{O}) \mathrm{N} \_7 \%$ was collected, see Figure $2 \mathrm{~b}$. The N K-edge features are contributed by unoccupied N 2p-derived states and the states of neighboring cations. The first triple peak features are mainly contributed by $\mathrm{N} 2 \mathrm{p}-\mathrm{Al}$ antibonding interactions while the feature at the broad band at $\mathrm{D}_{\mathrm{N}}$ is assigned mostly to $\mathrm{Al}-\mathrm{Al}$ antibonding. ${ }^{39}$

The lineshapes agree well with the $\mathrm{N} \mathrm{K}$-edge reported $\mathrm{in}^{48}$ for AlN and partially oxidized AlN. The relative higher intensity of the first peak at $401 \mathrm{eV}$ in $\mathrm{Ce}-\mathrm{Al}(\mathrm{O}) \mathrm{N} \_7 \%$ compared to the corresponding peak in $\mathrm{Ce}-\mathrm{Al}(\mathrm{O}) \mathrm{N} \_2 \%$ is attributed to the formation of locally trapped $\mathrm{N}_{2}$ molecules subsequent to the substitution of N-site by oxygen atoms. ${ }^{48}$ This further indicates that a critical content of oxygen (7\%) is required to induce a significant change in the local structure and related reduction of $\mathrm{Ce}$ from $4+$ to $3+$. This is consistent with the predominance of $\mathrm{Ce}^{3+}$ in $\mathrm{Ce}-\mathrm{Al}(\mathrm{O}) \mathrm{N} \_7 \%$ unlike $\mathrm{Ce}-\mathrm{Al}(\mathrm{O}) \mathrm{N} \_2 \%$ that predominantly contains $\mathrm{Ce}^{4+}$. Hence, from the above local chemistry investigations, it can be concluded that the detected $\mathrm{Ce}$ emission mostly originates from $\mathrm{Ce}^{3+}$ isolated in the $\mathrm{Al}(\mathrm{O}) \mathrm{N}$ matrix.

II) From electronic structure point of view 
When oxygen is incorporated in AlN, it substitutes nitrogen atoms and forms $\mathrm{O}_{\mathrm{N}}{ }^{+}$deep donor levels in the AlN bandgap. ${ }^{49-50}$ This is accompanied by the release of an electron for charge compensation. This electron can be captured by $\mathrm{Ce}^{4+}$ ions to stabilize $\mathrm{Ce}^{3+}$ state even in the as-deposited samples. However, the concentration of oxygen is found to be critical in order to activate sufficient amount of $\mathrm{Ce}^{3+}$. This interpretation is consistent with our EELS measurements showing the predominance of $\mathrm{Ce}^{3+}$ in the $\mathrm{Al}(\mathrm{O}) \mathrm{N}_{-} 7 \%$ sample before and after annealing, unlike for $\mathrm{Al}(\mathrm{O}) \mathrm{N} \_2 \%$ sample. The concept of valence state change of Ce ions can be used to interpret the previously reported ${ }^{5}$ optical activation of Ce by $\mathrm{Si}$ in AlN powder. The authors demonstrated the absence of PL from Ce-doped AIN powder without co-doping by $\mathrm{Si}^{4+}$ ions. Although they could not determine the role of $\mathrm{Si}^{4+}$ in the PL, the valence state change of $\mathrm{Ce}$ from +4 to +3 can explain this behavior. $\mathrm{Si}^{4+}$ substitutes $\mathrm{Al}$ and forms a donor level, $\mathrm{Si}_{\mathrm{Al}}{ }^{+}$, which releases an electron for charge compensation. ${ }^{51}$ This electron canbe captured by $\mathrm{Ce}^{4+}$ ion to form optically active $\mathrm{Ce}^{3+}$; hence the PL can be activated. This observation supports our interpretation about the role of donor level played by oxygen in our case. Thus, in order to activate the photoluminescence, introduction of donor levels is needed to generate electrons reducing $\mathrm{Ce}^{4+}$ to $\mathrm{Ce}^{3+}$. However, it is certainly a better option to use oxygen to play this role in AlN as it is a permanent impurity inside AlN. Hence, the difficulty to free AlN from oxygen can be turned into advantage by activating the PL in Ce-doped aluminum (oxy)nitride. Furthermore, it has been established that oxygen enters the AIN matrix to form $\mathrm{Al}_{2} \mathrm{O}_{3}$-likelocal states, which leads to generate one $\mathrm{Al}$ vacancy $\left(\mathrm{V}_{\mathrm{Al}}\right)^{3-}$ every three oxygen incorporated on nitrogen sites. The $\mathrm{Al}$ vacancy $\left(\mathrm{V}_{\mathrm{Al}}\right)^{3-}$ introduces an acceptor level inside the forbidden bandgap of AlN.

For confirming this modifications in the electronic structure and figure out why annealing activates the PL, Photoluminescence excitation (PLE) of the annealed samples has been measured. Figure $2 \mathrm{c}$ displays the PLE spectra for $\mathrm{Ce}-\mathrm{Al}(\mathrm{O}) \mathrm{N} \_7 \%$ RTA, Ce- 
$\mathrm{Al}(\mathrm{O}) \mathrm{N} \_13 \%$ RTA and $\mathrm{Ce}-\mathrm{Al}_{2} \mathrm{O}_{3} \_\mathrm{RTA}$. The PLE spectra of the oxynitrides reveal two main broad bands located around 3.74-3.86 eV and $4.9 \mathrm{eV}$, while that of aluminum oxide exhibits only one broad excitation band centered at $3.99 \mathrm{eV}$, indicating a significant difference in the excitation mechanisms between oxynitride and oxide films. The absorption peaks around 3.7 to $4 \mathrm{eV}$ can be ascribed to the overlapping between the absorption band of $\mathrm{Ce}^{3+}$ and that of $\left(\mathrm{V}_{\mathrm{Al}}-\mathrm{O}_{\mathrm{N}}\right)^{2-}$ stable defect complex in the $\mathrm{Al}(\mathrm{O}) \mathrm{N}$ matrix. The absorption band from 4.6 to $5 \mathrm{eV}$ is usually referred to $\left(\mathrm{V}_{\mathrm{Al}}-2 \mathrm{O}_{\mathrm{N}}\right)^{-}$defect complex, found at higher oxygen content. ${ }^{50,52-53}$ This defect complex acts as a donor (D) - acceptor (A) pair (D: Oxygen, A: $\mathrm{V}_{\mathrm{Al}}$ ) and participates to the energy transfer from the host matrix to the emitting ions. ${ }^{3}$ As annealing generates Al-O bonds and triggers the formation of $\mathrm{V}_{\mathrm{Al}}$, its role on PL activation through both excitation routes appears evident. Nevertheless, under excess of oxygen, as in $\mathrm{Al}_{2} \mathrm{O}_{3}$ sample, the PLE band close to $5 \mathrm{eV}$ is drastically quenched. Upon incorporation of a large oxygen amount, the density of $\mathrm{V}_{\mathrm{Al}}$ is likely decreased due to the coupling of excess oxygen to $\mathrm{V}_{\mathrm{Al}}$ and occupancy of the $\mathrm{V}_{\mathrm{Al}}$ sites by $\mathrm{O}$ atoms, as reported by Kita, T. et $\mathrm{al}^{3}$ in the case of Gd-doped AlN. Hence, the density of $\mathrm{V}_{\mathrm{Al}}-2 \mathrm{O}_{\mathrm{N}}$ defect complex is reduced and the energy transfer path from this defect to the activator " $\mathrm{Ce}^{3+"}$ is blocked. So, the only remaining excitation route is the PLE band around $4 \mathrm{eV}$ dominated by the absorption of $\mathrm{Ce}^{3+}$ as the density of the defect complexes is supposed to be reduced. Therefore, A schematic model about PL activation in Ce-doped oxynitride can be proposed involving $\mathrm{O}_{\mathrm{N}}, \mathrm{V}_{\mathrm{Al}}^{3+}$ and $\mathrm{Ce}_{\mathrm{Al}}{ }^{54-55}$, see schematic Figure $2 \mathrm{~d}$. Substituting N-site by oxygen results in releasing one electron that is captured by proximity $\mathrm{Ce}^{4+}$ to form $\mathrm{Ce}^{3+}$. Interaction of $\mathrm{O}_{\mathrm{N}}$ center with nearby $\left(\mathrm{V}_{\mathrm{Al}}\right)^{3-}$ has a strong driving force to form $\mathrm{V}_{\mathrm{Al}}-\mathrm{O}_{\mathrm{N}}$ defect complexes. ${ }^{50}$ Such defect centers are important for the optical excitation of Ce ions, as discussed in the PLE. 
In summary, oxygen not only assists in changing the valence state of Ce to the optically active state and in forming defect complexes that participate in the excitation of $\mathrm{Ce}^{3+}$, but also offers different local environments leading to higher emission intensity.

\section{4- White light approach}

The abovementioned findings point to the major and important role of oxygen to control the emission and excitation processes of Ce ions through: a) The local environment around $\mathrm{Ce}$ ions, b) The host defects. Different contents of oxygen modify the local chemistry and the density of oxygen related defects. Besides the role of these defects in the excitation process of Ce, they are also known to emit in the visible range $(400-600 \mathrm{~nm})$. Orange and yellow emissions from undoped AlN have been reported. ${ }^{56-58}$

In order to discriminate the radiative contribution from the host defects, two undoped Al(O)N_7\%_RTA with $200 \mathrm{~nm}$ and $\sim 9 \mu \mathrm{m}$ film thicknesses were prepared. The PL of these two samples, Figure3a, shows wide spectra with two peaks located at around $530 \mathrm{~nm}$ (green region) and $600 \mathrm{~nm}$ (orange region). The combination between these two peaks give rise to eye-observed yellow-orange emission from the thick sample $9 \mu \mathrm{m}$, as shown in the photo of Figure $3 b$. This evidences the radiative contribution from the host defects that should be considered overlapping with the emission from $\mathrm{Ce}$ ions in the previous doped samples, despite the small contribution in film thickness of $200 \mathrm{~nm}$. However this contribution is significantly improved at higher thickness due to increase in the number of radiative defects through the entire film thickness compared to the thin sample. 

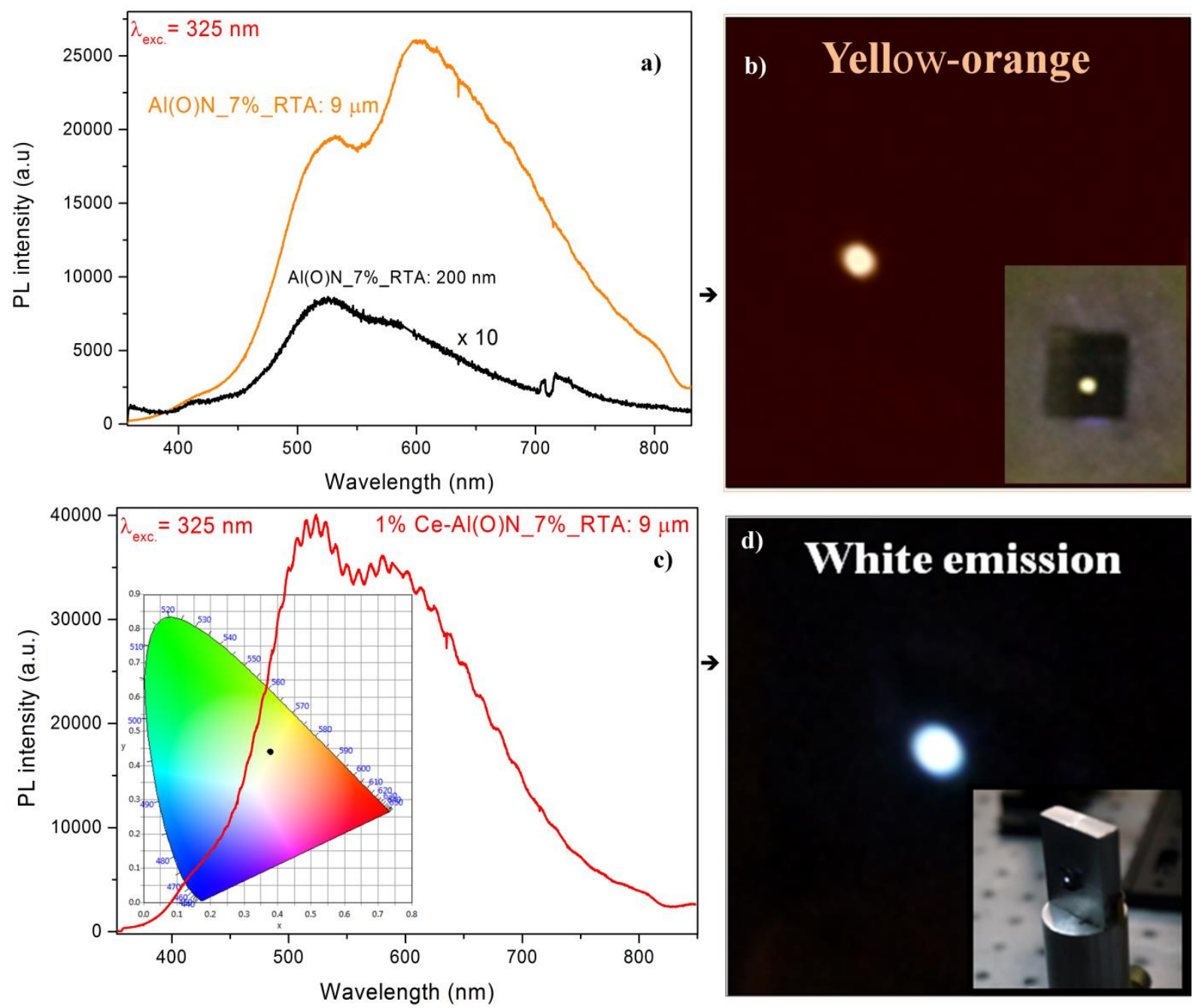

Figure 3.a) PL spectra of undoped $\mathrm{Al}(\mathrm{O}) \mathrm{N} \_7 \%$ RTA samples with two different thickness $200 \mathrm{~nm}$ and $9 \mu \mathrm{m}$. b) is the corresponding eye observed emission color from $\mathrm{Al}(\mathrm{O}) \mathrm{N} \_7 \%$ RTA thick sample. c) PL spectra of $1 \% \mathrm{Ce}-$ $\mathrm{Al}(\mathrm{O}) \mathrm{N} \_7 \%$ RTA sample with thickness $9 \mu \mathrm{m}$. Inset fig. is the corresponding CIE chromaticity diagram. d) is the corresponding eye observed white color from the thick Ce-doped sample.

A $1 \%$ Ce-doped $\mathrm{Al}(\mathrm{O}) \mathrm{N} \_7 \%$ RTA sample with $9 \mu \mathrm{m}$ thickness was prepared in order to examine the possibility to combine strong emissions from defects in the host matrix and from Ce ions. Interestingly, the PL spectrum of this sample, Figure 3c, exhibits broad band covers almost the visible region (400-800 nm) with two maxima at around $500 \mathrm{~nm}$ and $600 \mathrm{~nm}$. It is worth to mention that very similar PL spectra with two maxima at around $500 \mathrm{~nm}$ and 600 $\mathrm{nm}$ have been reported by A.T. Wieg et $\mathrm{al}^{19}$ on broadband emission from Ce-doped bulk AlN. This similarity supports the findings and shows that the two works corroborate each other. 
Strong white light emission is observed by the naked eye under excitation by $325 \mathrm{~nm}$, as shown in the photo Figure 3d.

The CIE chromaticity diagram of this sample, inset Figure 3c, shows that the emission color coordinates near to the white light region with color temperature of $4432 \mathrm{~K}$, which is an appealing cool white (white with bluish hue). This approach demonstrates the possibility of producing white light from single doped phosphor in a single thin film without the need to perform color mixing between several phosphors. In addition, $\mathrm{Al}(\mathrm{O}) \mathrm{N}$ material exhibits high thermal conductivity that can dissipate the excess heat, which is compatible with high power operation sources. This makes Ce-doped $\mathrm{Al}(\mathrm{O}) \mathrm{N}$ material an excellent candidate in white light generation racetrack. Although A.T. Wieg et $\mathrm{al}^{19}$ recently reported on white light emission from Ce-doped bulk AlN, white light emission in thin film structure is an important step towards white light integration in optoelectronic technology. We hope this work will act as a seed by providing new phosphor material for the development of white light sources based on chip technology.

\section{Conclusion}

Crystalline thin films of $\mathrm{Ce}-\mathrm{Al}(\mathrm{O}) \mathrm{N}$ have been prepared by reactive magnetron sputtering. The XRD, TEM, and HRTEM results show that microstructure modification is induced by incorporation of oxygen. In addition, EELS measurements have been used to probe the oxidation state of Ce ions and bonding in the host matrix. It is found that presence of critical amount of oxygen in this material is essential for sensitizing the photoluminescence. Oxygen plays a major role not only in converting Ce ions from the optically inactive state +4 to the optically active one +3 but also to lead to the formation, during annealing, of defect complexes between $\mathrm{V}_{\mathrm{Al}}$ and $\mathrm{O}_{\mathrm{N}}$ that participate in the excitation mechanism. This double role 
of oxygen is confirmed by EELS and PLE measurements. This model is confirmed by the interpretation of the PL behavior observed at high oxygen concentrations in Ce-doped nanocrystalline alumina. Manipulation of the emission color between blue and green is also evidenced and related to variations in the intensity and position of PL peak and O/N coordination ratio. Finally, white light emission is demonstrated by adjusting the film thickness and engineered overlapping of emissions by defects in the matrix and by Ce ions. We believe, this approach leads to better understanding the PL behavior of $\mathrm{Ce}$ ions in oxynitride materials and paves the way towards the development of devices showing specific and controllable emission colors.

\section{Acknowledgments}

A.E. Giba thanks Erasmus mundus scholarship that financially funded this work within the DocMASE program. He also thanks the "Université franco-allemande" (UFA) for supporting his travel and stay to Saarland University within the PhD-track in Materials Science and Engineering.

\section{References}

1. Muthu, S.; Schuurmans, F. J.; Pashley, M. D. In Red, Green, and Blue LED Based White Light Generation: Issues and Control, Conference Record of the 2002 IEEE Industry Applications Conference. 37th IAS Annual Meeting (Cat. No.02CH37344), 13-18 Oct. 2002; 2002; pp 327-333 vol.1.

2. Marchand, R.; Laurent, Y.; Guyader, J.; L'Haridon, P.; Verdier, P. Nitrides and Oxynitrides: Preparation, Crystal Chemistry and Properties. J. Eur. Ceram. Soc. 1991, 8, 197-213.

3. Kita, T.; Ishizu, Y.; Tsuji, K.; Harada, Y.; Chigi, Y.; Nishimoto, T.; Tanaka, H.; Kobayashi, M.; Ishihara, T.; Izumi, H. Thermal Annealing Effects on Ultra-Violet Luminescence Properties of Gd Doped AIN. J. Appl. Phys. 2015, 117, 163105. 
4. Lozykowski, H. J.; Jadwisienczak, W. M.; Bensaoula, A.; Monteiro, O. Luminescence and Excitation Mechanism of Pr, Eu, Tb and Tm Ions Implanted into AIN. Microelectron. J. 2005, 36, 453455.

5. Liu, T.-C.; Kominami, H.; Greer, H. F.; Zhou, W.; Nakanishi, Y.; Liu, R.-S. Blue Emission by Interstitial Site Occupation of $\mathrm{Ce}^{3+}$ in AIN. Chem. Mater. 2012, 24, 3486-3492.

6. Wang, W.; Zhang, P.; Wang, X.; Lei, X.; Ding, H.; Yang, H. Bifunctional AIN:Tb Semiconductor with Luminescence and Photocatalytic Properties. RSC Adv. 2015, 5, 90698-90704.

7. Weingärtner, R.; Erlenbach, O.; Winnacker, A.; Welte, A.; Brauer, I.; Mendel, H.; Strunk, H. P.; Ribeiro, C. T. M.; Zanatta, A. R. Thermal Activation, Cathodo- and Photoluminescence Measurements of Rare Earth Doped (Tm, Tb, Dy, Eu, Sm, Yb) Amorphous/Nanocrystalline AIN Thin Films Prepared by Reactive Rf-Sputtering. Opt. Mater. 2006, 28, 790-793.

8. Wieg, A. T.; Grossnickle, M. J.; Kodera, Y.; Gabor, N. M.; Garay, J. E. Nd:AlN Polycrystalline Ceramics: A Candidate Media for Tunable, High Energy, near IR Lasers. Appl. Phys. Lett. 2016, 109, 121901.

9. Koubaa, T.; Dammak, M.; Kammoun, M.; Jadwisienczak, W. M.; Lozykowski, H. J.; Anders, A. Spectra and Energy Levels of $\mathrm{Yb}^{3+}$ in AIN. J. Appl. Phys. 2009, 106, 013106.

10. Sontakke, A. D.; Ueda, J.; Xu, J.; Asami, K.; Katayama, M.; Inada, Y.; Tanabe, S. A Comparison on $\mathrm{Ce}^{3+}$ Luminescence in Borate Glass and YAG Ceramic: Understanding the Role of Host's Characteristics. J. Phys. Chem. C 2016, 120, 17683-17691.

11. Martin, N. Scintillation Detectors for X-Rays. Meas. Sci. Technol. 2006, 17 , R37.

12. Zhao, Z.; Yang, Z.; Shi, Y.; Wang, C.; Liu, B.; Zhu, G.; Wang, Y. Red-Emitting Oxonitridosilicate Phosphors $\mathrm{Sr}_{2} \mathrm{SiN}_{2} \mathrm{O}_{4-1.52}: \mathrm{Eu}^{2+}$ for White Light-Emitting Diodes: Structure and Luminescence Properties. J. Mater. Chem. C 2013, 1, 1407-1412.

13. Wierer, J. J.; Tsao, J. Y.; Sizov, D. S. Comparison between Blue Lasers and Light-Emitting Diodes for Future Solid-State Lighting. Laser Photonics Rev. 2013, 7, 963-993. 
14. Balter, M.; Li, S.; Morimoto, M.; Tang, S.; Hernando, J.; Guirado, G.; Irie, M.; Raymo, F. M.; Andreasson, J. Emission Color Tuning and White-Light Generation Based on Photochromic Control of Energy Transfer Reactions in Polymer Micelles. Chem. Sci. 2016, 7, 5867-5871.

15. Parganiha, Y.; Kaur, J.; Dubey, V.; Murthy, K. V. R. Near UV-Blue Emission from Ce Doped $\mathrm{Y}_{2} \mathrm{SiO}_{5}$ Phosphor. Mater. Sci. Semicond. Process. 2015, 31, 715-719.

16. Kim, C.-G. Green Emission from Cerium Hydroxide Layers Formed in $\mathrm{Si} / \mathrm{In} / \mathrm{CeO}_{2} / \mathrm{Si}$ Structures. Appl. Phys. Lett. 2001, 79, 3047-3049.

17. Bindu, K. R.; Anila, E. I. Greenish Yellow Emission from Wurtzite Structured ZnS:Ce Nanophosphor Synthesized at Low Temperature. J. Lumin. 2017, 192, 123-128.

18. Jang, H. S.; Kang, J. H.; Won, Y.-H.; Lee, S.; Jeon, D. Y. Mechanism for Strong Yellow Emission of $\mathrm{Y}_{3} \mathrm{Al}_{5} \mathrm{O}_{12}: \mathrm{Ce}^{3+}$ Phosphor under Electron Irradiation for the Application to Field Emission Backlight Units. Appl. Phys. Lett. 2007, 90, 071908.

19. Wieg, A. T.; Penilla, E. H.; Hardin, C. L.; Kodera, Y.; Garay, J. E. Broadband White Light Emission from Ce:AIN Ceramics: High Thermal Conductivity Down-Converters for LED and LaserDriven Solid State Lighting. APL Mater. 2016, 4, 126105.

20. Ishikawa, R., et al. Atomic Structure of Luminescent Centers in High-Efficiency Ce-Doped WAIN Single Crystal. Sci. Rep. 2014, 4, 3778.

21. Ishikawa, R.; Mishra, R.; Lupini, A. R.; Findlay, S. D.; Taniguchi, T.; Pantelides, S. T.; Pennycook, S. J. Direct Observation of Dopant Atom Diffusion in a Bulk Semiconductor Crystal Enhanced by a Large Size Mismatch. Phys. Rev. Lett. 2014, 113, 155501.

22. Aldabergenova, S. B.; Osvet, A.; Frank, G.; Strunk, H. P.; Taylor, P. C.; Andreev, A. A. Blue, Green and Red Emission from $\mathrm{Ce}^{3+}, \mathrm{Tb}^{3+}$ and $\mathrm{Eu}^{3+}$ Ions in Amorphous GaN and AIN Thin Films. J. NonCryst. Solids 2002, 299-302, Part 1, 709-713.

23. Giba, A. E.; Pigeat, P.; Bruyere, S.; Rinnert, H.; Soldera, F.; Mücklich, F.; Gago, R.; Horwat, D. Strong Room-Temperature Blue Emission from Rapid-Thermal Annealed Cerium-Doped Aluminum (Oxy)Nitride Thin Films. ACS Photonics 2017. 
24. Giba, A. E.; Pigeat, P.; Bruyère, S.; Easwarakhanthan, T.; Mücklich, F.; Horwat, D. Controlling Refractive Index in AIN Films by Texture and Crystallinity Manipulation. Thin Solid Films 2017, 636, 537-545.

25. Yan, Y.; Terauchi, M.; Tanaka, M. Structures of Polytypoids in AlN Crystals Containing Oxygen. Philos. Mag. A 1998, 77, 1027-1040.

26. Youngman, R. A.; Harris, J. H. Luminescence Studies of Oxygen-Related Defects in Aluminum Nitride. J. Am. Ceram. Soc. 1990, 73, 3238-3246.

27. Van Tendeloo, G.; Faber, K. T.; Thomas, G. Characterization of AIN Ceramics Containing LongPeriod Polytypes. J. Mater. Sci. 1983, 18, 525-532.

28. Zanatta, A. R. Effect of Thermal Annealing Treatments on the Optical Properties of RareEarth-Doped AIN Films. J. Phys. D: Appl. Phys. 2009, 42, 025109.

29. Wu, L.; Wiesmann, H. J.; Moodenbaugh, A. R.; Klie, R. F.; Zhu, Y.; Welch, D. O.; Suenaga, M. Oxidation State and Lattice Expansion of $\mathrm{CeO}_{2-\mathrm{x}}$ Nanoparticles as a Function of Particle Size. Phys.Rev.B 2004, 69, 125415.

30. Zavada, J. M.; Duhua, Z. Luminescence Properties of Erbium in III-V Compound Semiconductors. Solid State Electron. 1995, 38, 1285-1293.

31. Wilson, R. G.; Schwartz, R. N.; Abernathy, C. R.; Pearton, S. J.; Newman, N.; Rubin, M.; Fu, T.; Zavada, J. M. 1.54- $\mu$ m Photoluminescence from Er-Implanted GaN and AIN. Appl. Phys. Lett. 1994, 65, 992-994.

32. Ma, Y. Y.; Xiao, F.; Ye, S.; Zhang, Q. Y. In Luminescence Properties of Cerium Doped Silicon Nitride with Mgo Additive, 2013 IEEE 5th International Nanoelectronics Conference (INEC), 2-4 Jan. 2013; 2013; pp 459-462.

33. Ehre, F., et al. The Nitrogen Concentration Effect on Ce Doped $\mathrm{SiO}_{x} \mathrm{~N}_{\mathrm{y}}$ Emission: Towards Optimized $\mathrm{Ce}^{3+}$ for LED Applications. Nanoscale 2018, 10, 3823-3837.

34. Landrum, G. A.; Dronskowski, R.; Niewa, R.; DiSalvo, F. J. Electronic Structure and Bonding in Cerium (Nitride) Compounds: Trivalent Versus Tetravalent Cerium. Chem. Eur. J.1999, 5, 515-522. 
35. van Krevel, J. W. H.; Hintzen, H. T.; Metselaar, R.; Meijerink, A. Long Wavelength $\mathrm{Ce}^{3+}$ Emission in Y-Si-O-N Materials. J. Alloys Compd. 1998, 268, 272-277.

36. Pawade, V. B.; Dhoble, S. J. Spin-Orbit Splitting Difference and Stokes Shift in Cerium ${ }^{3+}$ Activated Aluminate Phosphors. Spectrosc. Lett. 2013, 46, 472-475.

37. Li, L.; Liang, H.; Tian, Z.; Lin, H.; Su, Q.; Zhang, G. Luminescence of $\mathrm{Ce}^{3+}$ in Different Lattice Sites of $\mathrm{La}_{2} \mathrm{CaB}_{10} \mathrm{O}_{19}$. J. Phys. Chem. C 2008, 112, 13763-13768.

38. Bouchet, D.; Colliex, C. Experimental Study of ELNES at Grain Boundaries in Alumina: Intergranular Radiation Damage Effects on Al-L23 and O-K Edges. Ultramicroscopy 2003, 96, 139-152. 39. Teruyasu, M. Overlap Population Diagram for ELNES and XANES: Peak Assignment and Interpretation. J. Phys. Condens. Matter 2009, 21, 104215.

40. Fan, X. J.; Bow, J. S.; Carpenter, R. W.; Lin, S. H.; Tian, S.-f. Al L Core Edge Fine Structure in Al, AIN and $\alpha-\mathrm{Al}_{2} \mathrm{O}_{3}$ : A Comparison of Microelectron Energy Loss Spectra with Theory. Acta Phys. Sin. (Overseas Edition) 1998, 7, 214.

41. Lozykowski, H. J.; Jadwisienczak, W. M. Thermal Quenching of Luminescence and Isovalent Trap Model for Rare-Earth-Ion-Doped AIN. phys. status solidi (b) 2007, 244, 2109-2126.

42. Lv, C.; Zhu, C.; Wang, C.; Li, D.; Ma, X.; Yang, D. Ultraviolet-Visible Electroluminescence from Metal-Oxide-Semiconductor Devices with $\mathrm{CeO}_{2}$ Films on Silicon. AIP Adv. 2015, 5, 037107.

43. Morshed, A. H.; Moussa, M. E.; Bedair, S. M.; Leonard, R.; Liu, S. X.; El-Masry, N. Violet/Blue Emission from Epitaxial Cerium Oxide Films on Silicon Substrates. Appl. Phys. Lett. 1997, 70, 16471649.

44. Garvie, L. A. J.; Buseck, P. R. Determination of $\mathrm{Ce}^{4+} / \mathrm{Ce}^{3+}$ in Electron-Beam-Damaged $\mathrm{CeO}_{2}$ by Electron Energy-Loss Spectroscopy. J. Phys. Chem. Solids 1999, 60, 1943-1947.

45. Filatova, E. O.; Konashuk, A. S.; Sakhonenkov, S. S.; Sokolov, A. A.; Afanas'ev, V. V. ReDistribution of Oxygen at the Interface between $\Gamma-\mathrm{Al}_{2} \mathrm{O}_{3}$ and TiN. Sci. Rep. 2017, 7, 4541.

46. Serin, V.; Colliex, C.; Brydson, R.; Matar, S.; Boucher, F. EELS Investigation of the Electron Conduction-Band States in Wurtzite Aln and Oxygen-Doped AIN(O). Phys. Rev. B 1998, 58, 5106-5115. 
47. Ogi, T.; Iwasaki, H.; Nandiyanto, A. B. D.; Iskandar, F.; Wang, W. N.; Okuyama, K. Direct White Light Emission from a Rare-Earth-Free Aluminium-Boron-Carbon-Oxynitride Phosphor. J.Mater. Chem. C 2014, 2, 4297-4303.

48. Maureen, M.; Alan, J. C. Quantifying the Oxidation of AIN Using Electron Energy Loss Spectroscopy. J. Phys. D 2000, 33, 1647.

49. Mattila, T.; Nieminen, R. M. Ab Initio Study of Oxygen Point Defects in GaAs, GaN, and AIN. Phys.Rev.B 1996, 54, 16676-16682.

50. Yan, Q.; Janotti, A.; Scheffler, M.; Walle, C. G. V. d. Origins of Optical Absorption and Emission Lines in AIN. Appl. Phys. Lett. 2014, 105, 111104.

51. Stampfl, C.; Van de Walle, C. G. Theoretical Investigation of Native Defects, Impurities, and Complexes in Aluminum Nitride. Phys.Rev.B 2002, 65, 155212.

52. Rosa, J.; Tale, I. Mechanism of Thermoluminescence in AIN:O. Czech J Phys B 1979, 29, 810824.

53. Slack, G. A.; Schowalter, L. J.; Morelli, D.; Freitas Jr, J. A. Some Effects of Oxygen Impurities on AIN and GaN. J. Cryst. Growth 2002, 246, 287-298.

54. Ishikawa, R., et al. Atomic Structure of Luminescent Centers in High-Efficiency Ce-Doped WAIN Single Crystal. Sci.Rep. 2014, 4, 3778.

55. Dar, A.; Majid, A. DFT Study of Cerium Doped Aluminum Nitride. Eur. Phys. J. Appl. Phys. 2015, 71, 10101.

56. Sedhain, A.; Du, L.; Edgar, J. H.; Lin, J. Y.; Jiang, H. X. The Origin of $2.78 \mathrm{eV}$ Emission and Yellow Coloration in Bulk AIN Substrates. Appl. Phys. Lett. 2009, 95, 262104.

57. Shen, L.; Wang, N.; Xiao, X. Strong Orange Luminescence from AIN Whiskers. Mater. Lett. 2013, 94, 150-153.

58. Jin, L., et al. Observation of the Long Afterglow in AIN Helices. Nano Lett. 2015, 15, 65756581. 


\section{Graphical Abstract}




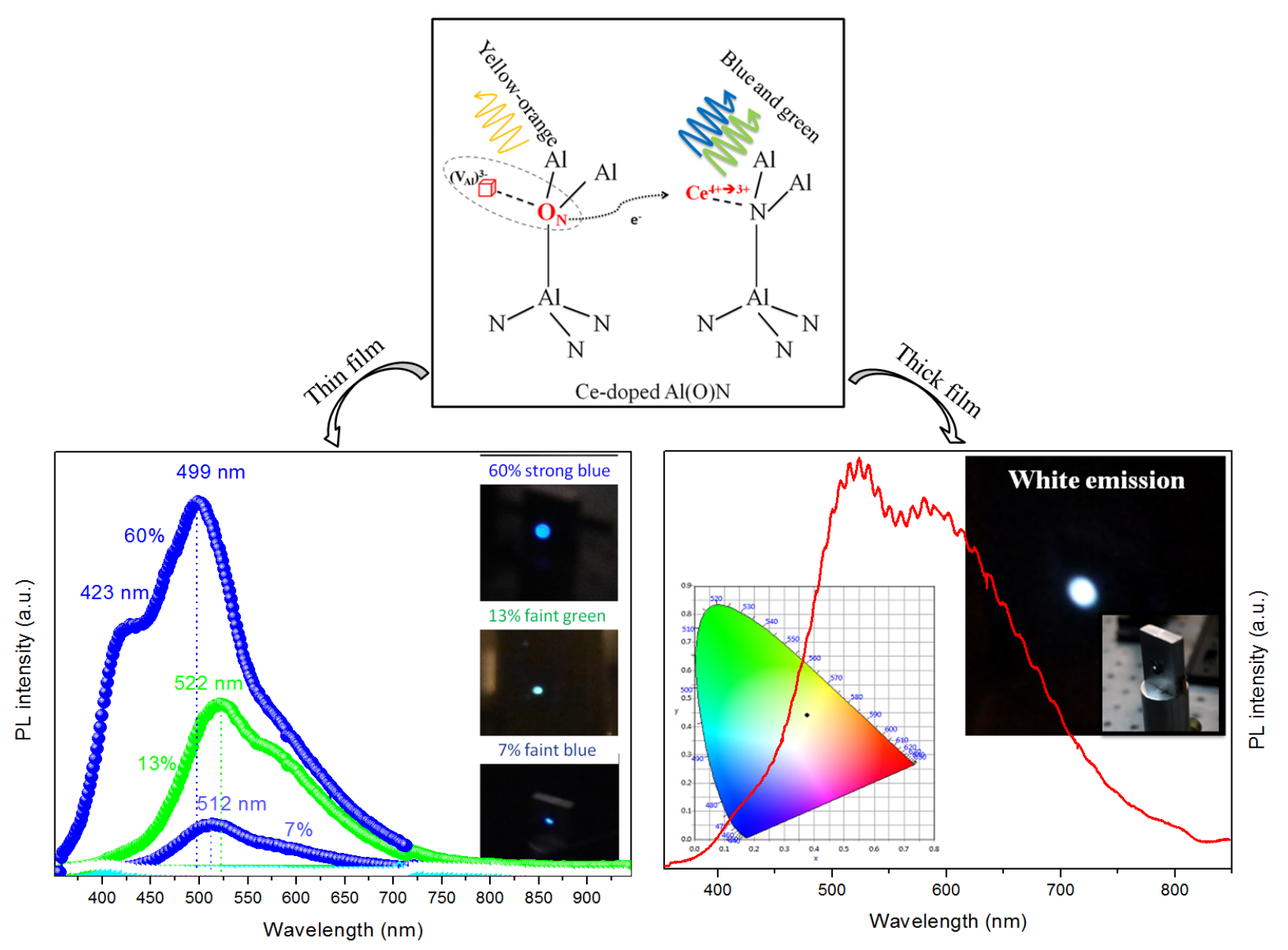

